\title{
Task Conflict and Relationship Conflict in Top Management Teams: The Pivotal Role of Intragroup Trust
}

Tony L. Simons and Randall S. Peterson

Cornell University

Task conflict is usually associated with effective decisions, and relationship conflict is associated with poor decisions. The 2 conflict types are typically correlated in ongoing groups, however, which creates a prescriptive dilemma. Three explanations might account for this relationship-misattribution of task conflict as relationship conflict, harsh task conflict tactics triggering relationship conflict, and misattribution of relationship conflict as task conflict. The authors found that intragroup trust moderates the relationship between task conflict and relationship conflict in 70 top management teams. This result supports the "misattribution of task conflict" explanation. The authors also found a weak effect that is consistent with the argument that tactical choices drive the association between the 2 conflict types. We infer that trust is a key to gaining the benefits of task conflict without suffering the costs of relationship conflict. 
Recent group process research distinguishes task conflict from relationship conflict and argues that the two have different performance consequences (e.g., Amason \& Sapienza, 1997; de Dreu, 1997; Jehn, 1995, 1997; O'Reilly, Williams, \& Barsade, 1998; Pelled, 1996; Pelled, Eisenhardt, \& Xin, 1999; Van de Vliert \& de Dreu, 1994). Jehn (1995) summarized the distinction well: Task conflict, or cognitive conflict, is a perception of disagreements among group members about the content of their decisions and involves differences in viewpoints, ideas, and opinions. Relationship conflict, or emotional conflict, is a perception of interpersonal incompatibility and typically includes tension, annoyance, and animosity among group members. Guetzkow and Gyr (1954) first identified the distinction between task and relationship conflict in groups. With a few recent exceptions (Friedman, Tidd, Currall, \& Tsai, 1998; O'Reilly et al., 1998), the distinction between task and relationship conflict in groups has survived over 40 years of scrutiny.

The distinction between task and relationship conflict is critical for both managerial prescription and theory development. Task conflict has usually been associated with two interrelated and beneficial effects. The first is group decision quality. Groups that experience task conflict tend to make better decisions than those that do not because task conflict encourages greater cognitive understanding of the issue being discussed. This effect has been found at both the individual level (Baron, 1991; Putnam, 1994) and the group level (Fiol, 1994; Janssen, Van de Vliert, \& Veenstra, 1999; Schweiger, Sandberg, \& Ragin, 1986; Schweiger, Sandberg, \& Rechner, 1989). A second beneficial effect of task conflict is affective acceptance of group decisions, A number of researchers have found that task conflict can lead to increased satisfaction with the group decision and a desire to stay in the group (Amason, 1996; Hoffman \& Maier, 1961; Korsgaard, Schweiger, \& Sapienza, 1995). Amason (1996) hypothesized that this link comes from the positive relationship between task conflict and the likelihood that group members will have the opportunity to voice their own perspective on issues being decided by the group (see also Folger, 1977). Voice, in turn, has long been associated with greater affective acceptance of group decisions (see Greenberg \& Folger, 1983; Lind \& Tyler, 1988, for reviews). More recently, Peterson (1997) has linked voice back to improved group decision quality as well as to greater affective acceptance of the decision. In sum, task conflict is generally associated with positive outcomes for group decisions.

The link between task conflict and group performance is not perfect, however. A number of scholars have noted recently that extremely high levels of task conflict sometimes lead to reduced member satisfaction and commitment to the team (e.g., Amason, 1996; Amason \& Sapienza, 1997; Jehn, 1997; Jehn \& Mannix, 1997; Schweiger, Sandberg, \& Ragin, 1986). Two recent studies have suggested that 
conflict duration plays a critical role here. Simons (1993) found that task conflict was associated with effective performance for top management teams where decisions were made quickly but that for slower decisions, task conflict was associated with low performance. Similarly, Peterson (1999a) found that task conflict led to frustration when it was coupled with very high levels of opportunity for voice (i.e., consensus decision making); that is, participants were particularly dissatisfied with the group process when one dissenting member of the group was allowed to substantially delay group decisions.

Relationship conflict, the perception of personal animosities and incompatibility, may be described as the shadow of task conflict. Research on relationship conflict has a long history in the literature dating from the earliest studies of conflict (e.g., Deutsch, 1969; Evan, 1965; Guetzkow \& Gyr, 1954) to a number of more recent studies (e.g., Gladstein, 1984; Janssen et al., 1999; Jehn, 1995; Wall \& Nolan, 1986). These studies document the negative effects of relationship conflict on group satisfaction and commitment. Relationship conflict also negatively affects group decision quality in three interrelated ways. First, relationship conflict limits the information processing ability of the group because group members spend their time and energy focusing on each other rather than on the group problems (Evan, 1965; Jehn \& Mannix, 1997). Second, relationship conflict limits group members' cognitive functioning by increasing their stress and anxiety levels (Jehn \& Mannix, 1997; Staw, Sandelands, \& Dutton, 1981). Third, relationship conflict encourages antagonistic or sinister attributions for other group members' behavior, which can create a self-fulfilling prophecy of mutual hostility and conflict escalation (Baron, 1991; Janssen et al., 1999; Torrance, 1957; Walton, 1969). In sum, substantial literature has indicated that relationship conflict is detrimental to decision quality and to affective commitment to the group.

If task conflict tends to yield positive consequences and relationship conflict yields negative consequences, it seems that practical management scholars should simply encourage task conflict and discourage relationship conflict. This recommendation has been problematic, however, because almost all studies that measure perceptions of task and relationship conflict in groups have shown significant positive correlations between the two. Teams that report task conflict also tend to report relationship conflict. The 11 studies listed in Table 1 demonstrate the strong relationship between these two forms of conflict (range $r=-.17$ to .88, mean $r-.47$ ). Thus, efforts to stimulate potentially beneficial task conflict run a substantial risk of triggering detrimental relationship conflict. 
Existing research has not looked directly at the mechanisms through which these two sources of intragroup conflict are so tightly connected. The present study focuses specifically on the co-occurrence of task and relationship conflict and compares different proposed mechanisms for this co-occurrence. We apply this focus because an understanding of the social psychological reasons why the two conflict types tend to co-occur is critical for both theoretical and practical

Table 1

Correlations Between Task and Relationship Conflict in Past Studies

\begin{tabular}{lr}
\hline \multicolumn{1}{c}{ Study } & \multicolumn{1}{c}{$r$} \\
\hline Amason (1996); Amason \& Sapienza (1997) & .39 \\
de Dreu (1997) & .34 \\
Friedman, Tidd, Currall, \& Tsai (1998) & .84 \\
Janssen, Van de Vliert, \& Veenstra (1999) & .46 \\
Jehn (1995) & -.17 \\
Jehn \& Mannix (1997) & .55 \\
Jehn, Northrraft, \& Neale (1999) & .57 \\
O'Reilly, Williams, \& Barsade (1998) & .88 \\
Pelled, Eisenhardt, \& Xin (1999) & .45 \\
Peterson (1999b) & .40 \\
Present study & .55 \\
\hline
\end{tabular}

reasons. An articulated and validated model of the psychological mechanisms that link task and relationship conflict is critical for a conceptual understanding of group conflict but is also necessary for the generation of sensible advice on how to manage group decisions.

Scholars have offered at least three possible explanations for why task conflict and relationship conflict are consistently correlated. The first argument is that task conflict leads to relationship conflict through a process of misattribution. Group members constantly interpret the behavior of other group members-they infer intentions, appraise whether the source of the behavior they see is internal or external, and assess the completeness and accuracy of the arguments made by others. When this attribution process points toward personal attack (Jehn, 1997; Torrance, 1957) or hidden agendas (Amason, 1996; Amason \& Sapienza, 1997; Eisenhardt \& Bourgeois, 1988), task conflict triggers relationship conflict through a process of biased information processing and self-fulfilling prophecy (see Fiske \& Taylor, 1991, for a review of this process). Ambiguous behavior is interpreted as fitting the expectations one has about the group or individual involved, and this confirmed expectation can create a selffulfilling prophecy. When one person distrusts another, that person will interpret ambiguous conflict behaviors as sinister in intent and convey distrust through his or her conduct. The person whose behavior 
is interpreted as sinister, perceiving that he or she is distrusted, tends to reciprocate that distrust (Creed \& Miles, 1996; Zand, 1972).

Reciprocated distrust or trust is an intragroup phenomenon. Intragroup trust plays a critical role in the interpretation process. Trust has been variously conceptualized as unidimensional (e.g., Mayer, Davis, \& Schoolman, 1995) or multidimensional (e.g., Cummings \& Bromiley, 1996), but has typically been strongly associated with benevolence, honesty, and competence (Mayer et al., 1995). At the group level, trust entails generalized expectations for all group members (Zand, 1972). Thus, in terms of its influence on group discussions, trust may sink to its lowest common denominator and, through reciprocity, may exhibit "spirals" of enhancement or reduction (Zand, 1972). The generalized ascriptions of benevolence and honesty that are associated with intragroup trust are likely to exert critical influence on group members' interpretations of other group members' conflict behavior.

If task conflict triggers relationship conflict primarily through misattribution of task conflict behavior, then the context in which the interpersonal relationship is held should play a moderating role. If group members trust each other, they will be more likely to accept stated disagreements at face value and less likely to misinterpret task conflict behaviors by inferring hidden agendas or personal attacks as the driving force behind the behavior (Mishra, 1996). When group members do not trust each other, they are likely to interpret the ambiguous behavior of others negatively and infer relationship conflict as a plausible explanation for the behavior. Amason and Sapienza (1997) proposed and tested a similar mechanism in their argument that open discussion will seldom lead to relationship conflict when participants are oriented cooperatively. The misattribution trigger mechanism suggests the following hypothesis:

Hypothesis 1: Intragroup trust will negatively moderate the relationship between task conflict and relationship conflict.

This moderated relationship will be consistent with the proposition that task conflict will lead to perceptions of relationship conflict under conditions of low trust but not under conditions of high trust.

The second mechanism posited by conflict scholars is behavioral. In the process of task conflict, group members may use emotionally harsh language (Pelled, 1996), intimidation tactics, or ad homonym arguments. Participants can feel bruised, humiliated, offended, or even brutalized by the debate tactics of other group members. The hurt feelings that result from poorly managed or expressed task conflict can easily stimulate relationship conflict for two closely related reasons. First, harsh language is nonnormative. Such unexpected behavior is particularly salient for making causal attributions 
(Hilton \& Slugoski, 1986). Thus, harsh language is particularly likely to invoke an attribution of relationship conflict. The procedural justice literature supports the normative argument. Procedural justice scholars have found that people care deeply about being treated with respect (Tyler \& Lind, 1992). People react quite negatively to being treated with disrespect, even if their financial or distributive outcomes are favorable. Harsh language is likely to be interpreted as disrespectful, and hence, seen as an indicator of relationship conflict. Regardless of the attribution mode for the initial behavior, a disputant who feels abused by aggressive tactics is likely to experience personal animosity, which is, by definition, relationship conflict. This set of mechanisms may well underlie prevalent admonishments to train managers in conflict management techniques (Bottger \& Yetton, 1988) and to manage norms that dictate permissible and nonpermissible conflict behaviors (Jehn, 1997). To the extent that the linking mechanism between task and relationship conflict is the use of harsh, hurtful, or aggressive tactics, we would expect task conflict to lead to relationship conflict primarily when such tactics are used.

Hypothesis 2: The use of aggressive conflict management tactics will positively moderate the relationship between task conflict and relationship conflict.

This moderated relationship will be consistent with the proposition that task conflict will generate relationship conflict when aggressive tactics are prevalent, but not when such tactics are minimized.

Finally, conflict scholars have suggested that it is possible that relationship conflict could trigger task conflict in the form of an attempt by one group member to make life difficult for another (e.g., Jehn, 1995). One group member may try to sabotage any influence that the other might have by manufacturing task conflict. This mechanism is not well supported by attribution theory or by the conflict Literature, however. Correspondent inference theory suggests that consistent task disagreement directed at only one group member by only one other group member should be seen as being caused by something stable within the person exhibiting the disagreement (Jones \& Davis, 1965). Specifically, relationship conflict masquerading as task conflict should be interpreted correctly as relationship conflict because relationship conflict is stable across issues. Task conflict, on the other hand, should change from issue to issue. Top management teams, in particular, tend to process many issues simultaneously, so that team members should be able to gauge correctly whether the genesis of the conflict is in the task or the relationship. Indeed, Pelled (1996) made just such an argument about the confounding of task and relationship conflict. She argued that participants in cross-task conflicts are seldom fooled and are likely to correctly label the 
conflict as being personal in origin and thus, in essence, relationship conflict. Moreover, Jehn (1997) noted that there were very few such cases in her qualitative study of work groups. In addition to having weak theoretical and empirical support, this mechanism would be extremely difficult to test, as it would require issue-specific, longitudinal data. We therefore did not test the "sabotage" mechanism that links relationship conflict to task conflict.

\section{Method}

\section{Data Sample}

One hundred chief executive officers (CEOS) of multi-site U.S,based hotel companies verbally agreed to participate in this research in return for a benchmarked feedback report on their company's top management group dynamics. These companies were drawn from the American Hotel \& Motel Association membership directory, were U.S.based, and were owner-operators of at least three hotel properties.3 operating revenues for participating companies ranged from $\$ 1.9$ million to over $\$ 600$ million, with median revenues of $\$ 37$ million. The median participating company size was eight properties. The average company size was 42.8 properties, but excluding the largest two companies from this calculation dropped the average size to 23.5 properties. Fifty-two of the participating company CEOs identified their primary segment as "mid-priced," 13 defined theirs as "economy," and 16 defined theirs as "luxury."

Participants in the study had a 1-hr telephone interview with the principal investigator. During this interview, a group process survey was completed and the CEO identified the top management group as those people who are regularly involved in strategic decisions at the company. The typically identified top management group included the $\mathrm{CEO}$ and senior officers. After this interview, CEOs received a packet containing paper surveys to be completed and returned by all other identified top management group members. These paper-and-pencil surveys contained group process scales identical to those completed during the CEO interview. Seventy-nine of the 100 companies that agreed to participate and had a CEO interview returned at least one additional top management team (TMT) survey response, and 70 of these had near-complete participation, which was defined as only one or no nonresponding executives. To minimize concerns about nonresponse bias, we used only the data from the 70 companies for whom we had nearcomplete participation. Of these 70 companies, 54 of them had all executives responding, and 16 of them were missing only one survey response. The average identified top management team size was five people. To assess the impact of incomplete data, we rechecked our analyses using only companies that had 100\% participation ( $\mathrm{n}=54)$ and 
all companies with two or more executive responses, including the CEO $(\mathrm{n}=79)$. The results were substantively identical in all conditions.

There were 380 individual respondents. Eighty-one percent of the respondents were male. Respondents averaged 47 years of age and 20 years of industry experience, with 8.5 years of tenure with their top management group and 11.4 years of tenure with their company. Ninetyfive percent of the respondents classified themselves as Caucasian, 3\% as Asian, and 2\% as other. Twenty-seven percent of the respondents classified their functional background as general management, 22\% operations, 19\% finance, 11\% sales \& marketing, 6\% development \& acquisitions, 5\% human resources, $2 \%$ strategic planning, and 8\% other.

\section{Measures}

Whereas laboratory studies of conflict generally manipulate conflict behavior (e.g., Schweiger, Sandberg, \& Ragin, 1986), quantitative field studies typically rely on self-report. Certainly, manipulated conflict behavior in ad hoc groups differs in meaningful ways from spontaneously emergent conflict behavior in ongoing work groups, so the field studies are necessary and appropriate. One implication of self-report, though, is that associations between task and relationship conflict may have emerged from common method variance. However, some studies (e.g., Amason, 1996) have attenuated this source of error by examining dependent and independent variables from different informants within each work group. A second implication of self-report is a focus on subjective perceptions of conflict rather than on some objective measure of discrepant utterances or discrepant views. Useful distinctions can be made between the perception of difference, the expression of difference, and the existence of difference. While task conflict can conceivably be objectified by such distinctions, trust and relationship conflict are constructs that are fundamentally subjective in nature: If a participant perceives them, they exist. The present study focuses on perceived conflict as a critical element of organization members' reality.

We measured task conflict and relationship conflict using Jehn's (1995) four-item summative Likert-type scales to measure task conflict and relationship conflict. The items were tailored to reflect the executive group context and were slightly modified to enhance diversity of item phrasing. For example, "How much friction is there among members in your work unit?" was rendered as, "How much personal friction is there among members in your executive group?" "How much are personality conflicts evident..." was rendered as, "How much are personality clashes evident ...[emphasis added]. The question "How much emotional conflict is there among members in your work unit?" was deleted as potentially unclear and was replaced with "To what extent are grudges evident among members of your executive group?" Respondents rated the four questions for each construct from 1 = none 
to 5 = a very great deal, and the item responses were summed. Coefficient alphas for these scales were .78 for task conflict and .87 for relationship conflict.

We measured intragroup trust using a five-item summative Likerttype scale that has been used successfully with previous executive group samples. In this scale, respondents rated these questions from 1 = never to 7 = always, and the item responses were summed. Items assessed group members' perception of group-wide trust; their perception of group-wide expectations of truthfulness, integrity, and living up to one's word; and their sense of shared respect for group members' competence. These aspects of trust were assessed explicitly at a group level, following Zand (1972), and reflect elements of trust that have been widely agreed upon (e.g., Butler, 1991; Hosmer, 1995; Mayer et al., 1995; McAllister, 1995). The questions were phrased as extremes (e.g., "We are all certain that we cm fully trust each other." [emphasis added]) to attenuate ceiling effects that could emerge from social desirability. Reliability for the intragroup trust scale was strong, with an alpha of .89.

We measured aggressive conflict tactics using a scale based on the control dimension of Putnam and Wilson's (1982) Organizational Conflict Communication Inventory (OCCI). Items assessed group members' agreement with statements such as, "We stand firm in expressing our viewpoints during disagreements" and "We assert our opinions forcefully." Reliability for the four-item scale was moderate at an alpha of .65, which is similar to reliabilities achieved for the Putnam and Wilson (1982) scale in other samples (Wilson \& Waltman, 1988). An additional measure of aggressive conflict tactics consisted of a single item that was originally written and included as part of the control conflict management style scale but was dropped from it due to inadequate item-total correlation. The item reads simply, "We raise our voices at each other." We term this variable loudness.

All scale items are included in Table 2.

\section{Aggregation}

The unit of analysis was the top management group at each of these 70 companies. Thus, all individual survey responses were aggregated to the group level for further analysis. This aggregation is designed to reduce the impact of individual differences in perception within each company, thereby forming a more objective estimate of the group attributes and conduct. Furthermore, aggregation is necessary because individual group members' reports are interdependent and therefore should not be analyzed as separate data points. To justify aggregation of the studied variables, we computed the eta-squared statistic, which indicates whether any two people within the same top management group are more similar than two people who are in different top management groups. Eta-squared values for 
relationship conflict, task conflict, trust, control, and loudness were $.48, .38, .32, .36$, and .34 , respectively. These numbers exceed Georgopolous' (1986, p. 40) minimum criterion of .20, which indicates that it is appropriate to aggregate the variables to the group level for further analysis. To further assess aggregation we computed $R_{w g}$, (James, Demaree, \&. Wolf, 1984). $R_{w g}$ for the multi-item scales averaged .89, .90, .87, and .83, respectively. Single items are expected to show lower $R_{w g}$ scores than multi-item scales (James et al., 1984), and $R_{w g}$ for the single-item loudness scale averaged .68. We also computed intraclass correlation coefficients (ICC; James, 1982). ICC(1) for relationship conflict, task conflict, trust, control, and loudness was .33, .14, .13, .07, and .17, respectively. ICC(2) for these variables was $.70, .44, .43, .28$, and .50 , respectively. Note, further, that ICC(2) is conservative in that it supposes a subsample

Table 2

Factor Analysis of Intragroup Trust, Tactics, and Confict Items (Pattern Matrix)

\begin{tabular}{|c|c|c|c|c|}
\hline Item & $\begin{array}{l}\text { Task } \\
\text { conflict }\end{array}$ & $\begin{array}{l}\text { Relationship } \\
\text { conflict }\end{array}$ & Trust & Control \\
\hline $\begin{array}{l}\text { How much do these executives disagree about the content } \\
\text { of strategic decisions? }\end{array}$ & .76 & .05 & .07 & .08 \\
\hline $\begin{array}{l}\text { How frequently are there disagreements about ideas in } \\
\text { your executive group? }\end{array}$ & .80 & 09 & 07 & 00 \\
\hline $\begin{array}{l}\text { To what extent are there differences of professional } \\
\text { opinion in your executive group? }\end{array}$ & .80 & .02 & .03 & -.06 \\
\hline $\begin{array}{l}\text { How often do people in your executive group disagree } \\
\text { regarding the company's strategic decisions? }\end{array}$ & .64 & -.02 & -.24 & .16 \\
\hline $\begin{array}{l}\text { How much personal friction is there among members in } \\
\text { your executive group? }\end{array}$ & 18 & .68 & -.16 & -.09 \\
\hline $\begin{array}{l}\text { How much are personality clashes evident in your } \\
\text { executive group? }\end{array}$ & .09 & .76 & -.08 & -.05 \\
\hline $\begin{array}{l}\text { How much tension is there among members in your } \\
\text { executive group? }\end{array}$ & .13 & .72 & -.12 & -.17 \\
\hline $\begin{array}{l}\text { To what extent are grudges evident among members of } \\
\text { your executive group? }\end{array}$ & .19 & .67 & -.08 & -18 \\
\hline We absolutely respect cach other's competence. & -.01 & -.20 & .60) & .20 \\
\hline Every executive present shows absolute integrity. & .03 & -.11 & .80 & .02 \\
\hline We expect the cornplete truth from each other. & .03 & .08 & .86 & -.06 \\
\hline We are all certain that we can fully trust each other. & -.03 & -.14 & .80 & .03 \\
\hline We count on each other to fully live up to our word. & -.03 & -.01 & 86 & -.03 \\
\hline $\begin{array}{l}\text { We stand firm in expressing our viewpoints during } \\
\text { disagreements. }\end{array}$ & .13 & -.02 & -.02 & .72 \\
\hline Each of us takes a stand in the disagreement. & .15 & -.11 & .02 & .64 \\
\hline $\begin{array}{l}\text { We maintain our respective positions unless we are } \\
\text { persuaded by a teasonable argument. }\end{array}$ & -.09 & .00 & -.02 & .70 \\
\hline We assert our opinions forcefully. & .02 & .26 & .28 & .58 \\
\hline We raise our voices at each other. & -.11 & .58 & .01 & .11 \\
\hline
\end{tabular}

Note. Loadings greater than .40 are in boldface.

from an infinite pool of potential raters or informants, when, in these data, almost all possible informants are represented. These statistics tend to support aggregation of the data to the group level. 


\section{Analysis}

To assess the distinguishability of the measured constructs, we applied an exploratory factor analysis, with oblique rotation due to expected intercorrelations. As an additional test, we also applied a confirmatory factor analysis to these data. The hypothesized interaction effect was tested using hierarchical linear regression. In order to correct for the multicol-linearity that arises when testing moderated relationships among continuous variables, the independent variables were centered before interaction terms were generated, following a procedure proposed by Cohen and Cohen (1983) and further refined by Aiken and West (1991). Centering involves subtracting the sample mean from each independent variable so that the sample distribution is unchanged but the adjusted variable has a mean of zero. The interaction terms are computed by multiplying the centered variables together. Interaction terms were tested in regressions after all involved main effects had already been entered. Interaction analysis using the centering procedure is preferable to simpler analyses, because it yields readily interpretable coefficients that are relatively free of multicollinearity. Two-tailed significance tests of interaction-term coefficients were calculated after all main effects had already been entered into the regression.

Hypotheses were tested independently and were then combined into a single model to assess the extent to which tested effects are additive.

\section{Results}

Table 3 shows that many of the variables of interest were intercorrelated. Because of these expected intercorrelations, an exploratory factor analysis with oblique rotation was used to assess whether respondents were able to differentiate between relationship conflict, task conflict, trust, and aggressive tactics. This analysis, shown in Table 2, found that items measuring relationship conflict, task conflict, intragroup trust, and control tactics loaded appropriately on four factors with eigenvalues over L.O but that the loudness item loaded on the factor with relationship conflict. Confirmatory factor analysis was unable to assess the single-item variable as a unique factor, so that item was excluded. However, the remaining items appropriately fit the proposed four- factor model, with $x^{2} / d f=1.69$, goodness of fit index $=.95$, adjusted goodness of fit index $=.93$, root mean square residual $=.05$, and root mean square error of approximation $=.04$. These analyses show that respondents were able to distinguish task conflict, relationship conflict, trust, and aggressive tactics as separate constructs. The distinction between relationship conflict and loudness was not supported by exploratory factor analysis but is evident from inspection of the items. Relationship conflict questions ask about perceptions of personal 
friction, personality clashes, tension, and grudges. Loudness, in contrast, consists of the single item, "We raise our voices at each other." Thus, relationship conflict asks for introspection about underlying dynamics and emotional states, while loudness is a report of specific behavior. Loudness is correlated with relationship conflict at $r=.29$, which further supports the distinction between the two constructs.

The results of the moderated regression analyses, shown in Table 4, indicate that trust moderates the relationship between task conflict and relationship conflict in accord with Hypothesis 1 . In the main effects model, task conflict has a significant positive impact on relationship conflict, while trust has a significant negative impact. Thus, the impact of these two independent variables is additive and not substitutable. These two independent variables combined account for 52\% of the variance in relationship conflict.

Table 3

Descriptive Statistics and Zero-Order Correlations

\begin{tabular}{lrrrrrrr}
\hline \multicolumn{1}{c}{ Variable } & $M$ & $S D$ & 1 & 2 & 3 & 4 \\
\hline 1. Relationship conflict & 7.40 & 2.23 & - & & & \\
2. Task conflict & 10.23 & 1.41 & $.57^{* *}$ & - & & \\
3. Intragroup trust & 29.64 & 3.18 & $-.62^{* *}$ & $-.36^{* *}$ & - & \\
4. Control tactics & 18.40 & 2.04 & -.05 & .18 & $.39^{* *}$ & - \\
5. Loudness & 2.63 & 0.80 & $.29^{*}$ & $.27^{*}$ & -.03 & $.39^{* *}$ & - \\
\hline
\end{tabular}

${ }^{*} p<.05 . \quad * * p<.01$.

The addition of an interaction term between task conflict and trust accounts for an additional 6\% of the variance in relationship conflict. The b coefficient for this interaction term is significant and negative, which indicates that high levels of task conflict coupled with low levels of trust lead to high levels of relationship conflict. When trust levels are high, task conflict is only weakly related to relationship conflict.

Figure 1 illustrates the interaction from Table 4 by showing the slopes of regression lines linking task conflict to relationship conflict under conditions of average intragroup trust, high intragroup trust, and Low intragroup trust. Following Aiken and West (1991), these slopes were computed from $b$ coefficients derived from regression equations that adjust the interaction term to reflect different values of the moderator. Since there are no theoretically meaningful breakpoints in the continuous moderating variable of trust, high and low scores were defined as values one standard deviation above and below sample means, respectively. The values for high, average, and low trust are thus derived from our sample of top management teams and do not represent artificial extremes. The values for the independent 
variable in this graph, task conflict, range from approximately $-2 S D$ to $2 S D$.

The second two columns of Table 4 report the hierarchical regression test of Hypothesis 2, that aggressive conflict tactics moderate the link between task conflict and relationship conflict. This regression provided some surprises: In the main effects model, Table 4 Results of Hierarchical Moderated Regression Analysis Predicting Relationship Conflict

\begin{tabular}{|c|c|c|c|c|c|c|}
\hline \multirow[b]{2}{*}{ Variable } & \multicolumn{2}{|c|}{ Hypothesis 1} & \multicolumn{2}{|c|}{ Hypothesis 2} & \multicolumn{2}{|c|}{ Combined model } \\
\hline & $\begin{array}{l}\text { Main effects } \\
\text { model }\end{array}$ & $\begin{array}{c}\text { Moderated } \\
\text { model }\end{array}$ & $\begin{array}{c}\text { Main effects } \\
\text { model }\end{array}$ & $\begin{array}{c}\text { Moderated } \\
\text { model }\end{array}$ & $\begin{array}{c}\text { Main effects } \\
\text { model }\end{array}$ & $\begin{array}{c}\text { Moderated } \\
\text { model }\end{array}$ \\
\hline Task conflict & $\begin{array}{l}.64^{* * * *} \\
(.15)\end{array}$ & $\begin{array}{l}.52^{* * * * *} \\
(.14)\end{array}$ & $\begin{array}{l}.88^{* * * * *} \\
(.16)\end{array}$ & $\begin{array}{l}.81^{* * * * *} \\
(16)\end{array}$ & $\begin{array}{l}.55^{* * * * *} \\
(.15)\end{array}$ & $\begin{array}{l}41^{* *} \\
(15)\end{array}$ \\
\hline Intragroup trust & $\begin{array}{l}-.34^{* * * * *} \\
(.06)\end{array}$ & $\begin{array}{c}-.35 * * * * \\
(.06)\end{array}$ & & & $\begin{array}{l}-35^{* * * * *} \\
(.07)\end{array}$ & $\begin{array}{l}-.37 * * * * \\
(.07)\end{array}$ \\
\hline Control tactics & & & $\begin{array}{l}-.26^{*} \\
(.12)\end{array}$ & $\begin{array}{r}-.23 * \\
(.12)\end{array}$ & $\begin{array}{l}.01 \\
(.11)\end{array}$ & $\begin{array}{c}.06 \\
\text { (.11) }\end{array}$ \\
\hline Loudness & & & $\begin{array}{c}.66^{*} \\
(.30)\end{array}$ & $\begin{array}{l}.60^{*} \\
(.30)\end{array}$ & $\begin{array}{r}49 \dagger \\
(.26)\end{array}$ & $\begin{array}{r}41 \dagger \\
(.26)\end{array}$ \\
\hline Task Conflict $\times$ Intragroup Trust & & $\begin{array}{l}-.10^{* * * *} \\
(.04)\end{array}$ & & & & $\begin{array}{r}-.09 * \\
(.04)\end{array}$ \\
\hline Task Conflict $\times$ Control Tactics & & & & $\begin{array}{c}-.13 \\
(.08)\end{array}$ & & \\
\hline Task Conflict $\times$ Loudness & & & & $\begin{array}{l}.34 \div \\
(.18)\end{array}$ & & $\begin{array}{c}.15 \\
(.14)\end{array}$ \\
\hline$\Delta R^{2}$ & & $.06^{* * *}$ & & $.04 *$ & & $.06^{*}$ \\
\hline Model $R^{2}$ & $.52 * * * *$ & $.58^{* * * *}$ & $.39 * * * *$ & $.43^{* * * *}$ & $.55^{* * * * *}$ & $.61^{* * * * *}$ \\
\hline Adjusted $R^{2}$ & .51 & .56 & .36 & .39 & .53 & .58 \\
\hline
\end{tabular}

Note. Data reported are $b$-coefficients with standard errors in parentheses, $n=70$ groups.

$\dagger p<.10 . \quad * p<.05 . \quad * * p<.01 .^{* * *} p<.005 . \quad * * * * p<.001$.

discussion loudness showed a strong positive association with relationship conflict, while control tactics showed a significant negative association with relationship conflict. This main effect of control tactics was unexpected given the conceptualization of control tactics as aggressive and potentially offensive, the low direct correlation between control tactics and relationship conflict, and the high correlation between control tactics and loudness shown in Table 3. However, the relationship was revealed in a combined regression. The main effects model accounted for 39\% of the variance in relationship conflict.

In the moderated regression that reflects Hypothesis 2, the addition of interaction terms between task conflict and aggressive tactics was found to account for an additional 4\% of the variance in relationship conflict. The interaction term between control tactics and task conflict was not significant, but the interaction term between loudness and task conflict was positive and marginally significant. Thus, the results are marginally consistent with the hypothesis that task conflict, when voices are allowed to elevate, is more likely to lead to relationship conflict than when voices are not allowed to elevate. The slopes associated with the interaction between task conflict and loudness are shown in Figure 2. 
The fifth and sixth columns of Table 4 show a regression model that draws on the significant predictor variables from tests of Hypotheses 1 and 2. This combined regression model, designed to test the additivity of the uncovered effects, accounted for a total of 61\% of the variance in relationship conflict, with 6\% of that total emerging from the interaction terms. The combined R2 score of .61 is consistent with a small element of additivity among the tested

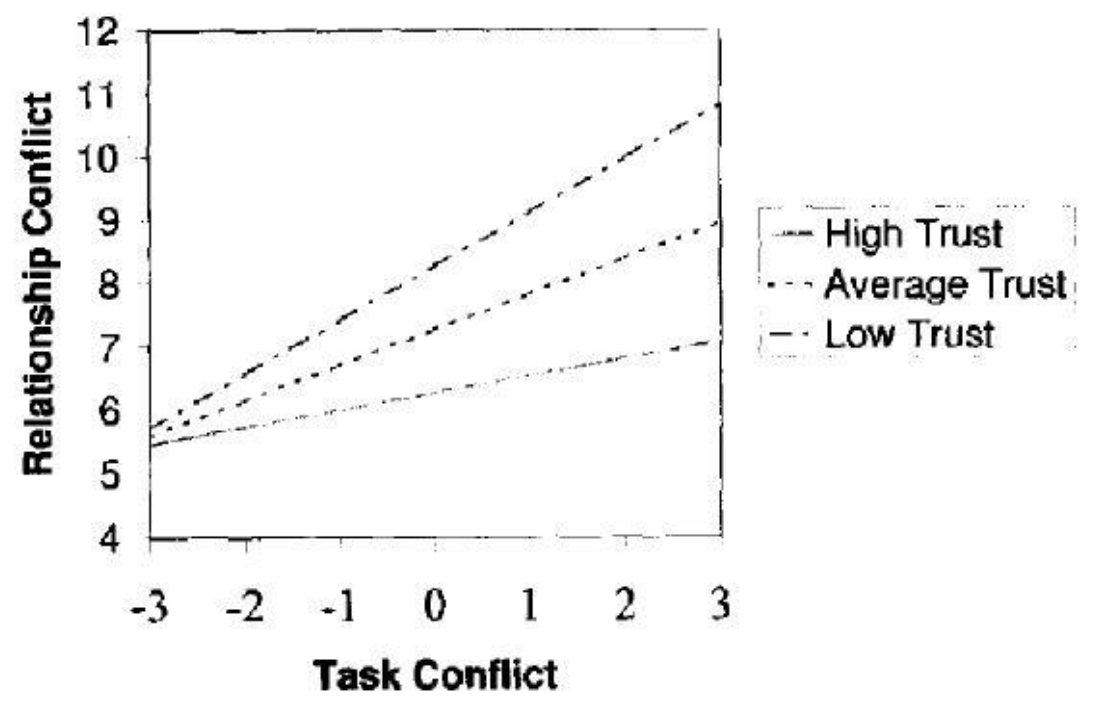

Figure 1. Computed slopes of regression line at sample average, high, and low intragroup trust.

predictors. In this pooled regression equation, all main effects were similar to the results of separate analyses. The interaction term between task conflict and trust remained significant, but the interaction term between task conflict and loudness dropped from marginal significance to nonsignificance.

\section{Discussion}

Our study examined the mechanisms that underlie the prevalent cooccurrence of task conflict and relationship conflict. Hypothesis 1 examined the interpretation and attribution process as a driving mechanism for this co-occurrence. This mechanism proposes that task conflict is often misattributed as being personal in nature or motive, and thus often leads to relationship conflict. Our data from ongoing top management groups was strongly consistent with Hypothesis 1. A negative, significant interaction term indicated that groups with low levels of intragroup trust displayed a much stronger positive association between task conflict and relationship conflict than did groups with high levels of intragroup trust. We interpret this result as being consistent with the proposition that trust reduces the likelihood of misattribution of task conflict. 
Our data were marginally consistent with Hypothesis 2, which examined the proposition that task conflict leads to relationship conflict through the use of harsh or forceful tactics. There was a marginally significant positive interaction term between task conflict and loudness, which is consistent with the notion that task conflict is more likely to lead to relationship conflict when it is expressed in raised voices than when it is not. The second operationalization of aggressive tactics, control tactics, did not yield a significant interaction term.

The examination of main effects for the hypothesis that aggressive conflict management tactics moderate the relationship

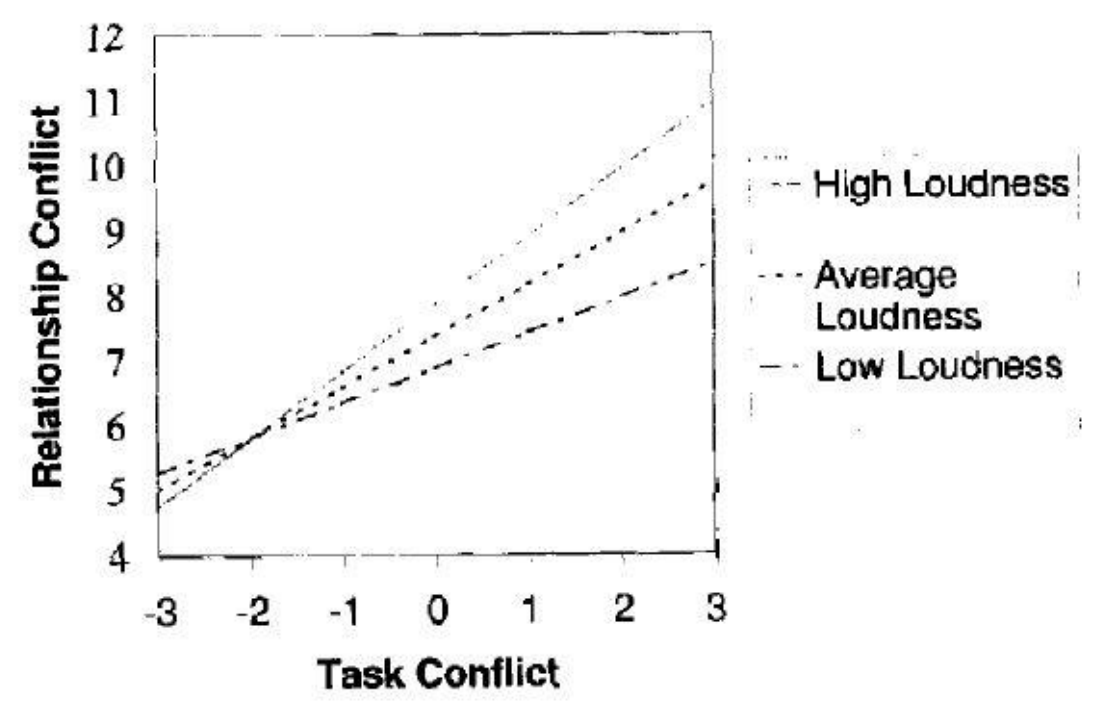

Figure 2. Computed slopes of regression line at sample average, high, and low discussion loudness at average levels of control tacties.

between task and relationship conflict yielded some surprising results. Though loudness and control tactics show a strong positive intercorrelation, in a regression combining the two they show opposite associations with relationship conflict. The coefficient for loudness was positive, and the coefficient for control tactics was negative. Thus, when loudness is held constant, positional argument may serve to reduce the experience of relationship conflict. This reduction might emerge from a process whereby the open expression of differing positions prevents those differences from festering, unexpressed, into relationship conflict. The process by which this festering occurs warrants further articulation and testing in future research.

As always, the results of one study should be greeted with some hesitation. Loudness was measured using only a single survey item, and control tactics assessed positional argument but did not assess the use of threats or of ad hominem attacks. These and other contentious tactics should be specifically tested for their ability to trigger relationship conflict. The marginally significant interaction term 
between task conflict and loudness suggests a relationship that may yield significant results in a more controlled and fully measured study.

Overall, these study results should be taken as strong evidence in support of the interpretation process as a mechanism that links task conflict to relationship conflict. Our data are very consistent with the notion that the interpretation process is active in generating the co-occurrence of task and relationship conflict. The data also provide limited support for aggressive conflict tactics as a mechanism that links task conflict to relationship conflict. The results of analyses are only marginally consistent with the proposed mechanism that aggressive tactics play a role in generating that cooccurrence. Confident assertions regarding the role of tactics will require further empirical research.

The practical implications of this result are important. Our result suggests that companies can realize the benefits of task conflict with minimal danger of relationship conflict if an appropriate basis of intragroup trust is established. This focus on intragroup trust represents a crucial amendment to the recommendations of Jams (1982), Tjosvold (1991), and others who have advocated task conflict as a remedy to groupthink and other organizational ills. The stimulation of task conflict as a primary intervention runs a high risk of unintentionally triggering relationship conflict, with all its attendant negative consequences. Our study suggests that task conflict stimulation interventions must be augmented by trust-generation interventions if negative consequences are to be avoided. Further, it complements the preliminary work of Amason and Sapienza (1997), who argued that openness without cooperation can lead to relationship or emotional conflict. While there is only sparse academic literature on the antecedents of trust in groups, the practitioner literature on trust-enhancement exercises is vast.

From a theory-development standpoint, the finding that trust moderates the connection between task conflict and relationship conflict enhances our understanding of the nature of all three constructs. It demonstrates primarily that interpretation processes play a central role in transforming one form of conflict into another. By showing that the link between the two kinds of conflict can be severed, this study reinforces the usefulness of the distinction and effectively counters arguments that the two are inseparable (e.g., Janssen et al., 1999) or are reflective of a single underlying construct (e.g., Williams \& O'Reilly, 1998).

A second implication of the study is a statement of the importance of group-level trust as a construct. Trust at a group level appears to play a pivotal role in group process, and this study offers 
a reliable and practical measure of the construct at the appropriate level of analysis.

As always, there are reasons to exercise caution in generalizing too much from one study. The most important limitation of this study is that it is cross-sectional in design. This design element limits our ability to make causal assertions. We could not directly test, for example, whether task conflict causes relationship conflict or whether they co-occur for a different reason. However, the moderated analyses make simple reverse-causality arguments less tenable. For example, a reverse-causal account for the Trust X Task Conflict interaction would assert that relationship conflict leads to task conflict if participants do not trust each other, but in the presence of trust there are fewer task conflict implications. This mechanism is not very parsimonious, but it may be feasible and should be tested longitudinally. A second limitation of this study is the risk of common-method variance or monomethod bias, as all studied variables emerged from the same survey instrument. Common method variance can artificially inflate bivariate correlations. The complex data relationships shown by a predicted interaction effect, however, are not easily explained by the common method (Brockner, Siegel, Daly, Tyler, \& Martin, 1997) because respondents cannot guess researcher hypotheses or respond in a socially desirable manner that would lead to spurious findings. Finally, this study focused exclusively on top management groups within a single industry, and it is conceivable that the tested relationships differ for different populations. The demographics of our sample, while perhaps representative of senior management groups, might limit generalization of our findings to other demographic groups. One might imagine that the mechanisms articulated by this study are specific to American White men in senior management positions. However, we see little a priori reason to expect differences between populations.

These methodological limitations should not be overstated. Previous studies demonstrate that relationship conflict in work groups tends to be associated with relatively poor organizational performance. Task conflict, on the other hand, is often beneficial. Our data are consistent with the notion that intragroup trust is key to preventing task conflict from escalating into relationship conflict, presumably through an attribution mechanism. We suggest, therefore, that advice to leaders should focus on trust among team members as a necessary complement to task conflict. The second proposed mechanism, that harsh task conflict tactics yield hurt feelings that, in turn, lead to relationship conflict, received only marginal support from these data. Further research is warranted to more fully articulate and explore the role of conflict management tactics as a second possible mechanism that links task conflict and relationship conflict. 


\section{References}

Aiken, L., \& West, S. (1991). Multiple regression: Testing and interpreting interactions. Newbury Park, CA: Sage.

Amason, A. C. (1996). Distinguishing the effects of functional and dysfunctional conflict on strategic decision making: Resolving a paradox for top management teams. Academy of Management Journal, $39,123-148$.

Amason, A. C., \& Sapienza. H. (1997). The effects of top management team size and interaction norms on cognitive and affective conflict. Journal of Management, 23, 495-516.

Baron, R. A. (1991). Positive effects of conflict: A cognitive perspective. Employee Responsibilities and Rights Journal, 2, 2536 .

Bottger, P. C., \& Yetton, P. (1988). An integration of process and decision scheme explanations of group problem-solving performance. Organizational Behavior and Human Decision Processes, 42, 234-249.

Brockner, J, Siegel, P. A., Daly, J. P., Tyler, T., \& Martin, C. (1997). When trust matters: The moderating effect of outcome favorability. Administrative Science Quarterly, 42, 558-583.

Butler, J. K., Jr, (1991). Toward understanding and measuring conditions of trust: Evolution of a conditions of trust inventory. Journal of Management, 17, 643-663.

Cohen, J., \& Cohen, P. (1983). Applied multiple regression/correlation analysis for the behavioral sciences. (2nd ed.). Hillsdale, NJ: Erlbaum.

Creed, W. E. D., \& Miles, R. E. (1996). Trust in organizations: A conceptual framework linking organizational forms, managerial philosophies, and the opportunity costs of controls. In R. M. Kramer \& T. R. Tyler (Eds.), Trust in organizations: Frontiers of theory and research (pp. 16-39). Thousand Oaks, CA: Sage.

Cummings, L. L, \& Bromiley, P. (1996). The Organizational Trust Inventory (OTI): Development and validation. In R, M. Kramer St, T. R, Tyler (Eds.), Trust in organizations: Frontiers of theory and research (pp. 302-330). Thousand Oaks, CA: Sage.

de Dreu, C. K. W. (1997). Productive conflict: The importance of conflict management and conflict issues. In C. K. W. de Dreu \& E. Van de Vliert (Eds.), Using conflict in organizations (pp. 9-23). London: Sage.

Deutsch, M. (1969). Conflicts: Productive and destructive. Journal of Social Issues, 25, 7-41. 
Eisenhardt, K. M., \& Bourgeois, J. L. Ill, (1988). Politics of strategic decision making in high velocity environments: Toward a midrange theory. Academy of Management Journal, 31, 737-770.

Evan, W. (1965). Conflict and performance in R\&D organizations. Industrial Management Review, 7, 37-46.

Fiol, C. M, (1994). Consensus, diversity and learning in organizations. Organization Science, 5, 403-420.

Fiske, S. T. \& Taylor, S. E, (1991). Social cognition (2nd ed). New York: McGraw-Hill.

Folger, R. (1977). Distributive and procedural justice: Combined impact of "voice" and improvement of experienced inequality. Journal of Personality and Social Psychology, 35, 108-119.

Friedman, R. A., Tidd, S. T., Currall, S. C., \& Tsai, J. C. (1998, June). Stewing in your own juices: The effects of conflict style on work environment and stress. Paper presented at the International Association for Conflict Management Conference, Washington, DC.

Georgopolous, B. S. (1986). Organizational structure, problem-solving, and effectiveness. San Francisco: Jossey-Bass.

Gladstein, D. (1984), A model of task group effectiveness. Administrative Science Quarterly, 29, 499-517.

Greenberg, J., \& Folger, R. (1983). Procedural justice, participation, and the fair process effect in groups and organizations. In P. B. Paulus (Ed.), Basic group processes (pp. 235-256). New York: Springer Verlag.

Guetzkow, H., \& Gyr, J. (1954). An analysis of conflict in decisionmaking groups. Human Relations, 7, 367-381.

Hilton, D. J., \& Slugoski, B. R. (1986). Knowledge-based causal attribution: The abnormal conditions focus model. Psychological Review, 93, 75-88.

Hoffman, L. R., \& Maier, N. R. F. (1961). Quality and acceptance of problem solutions by members of homogeneous and heterogeneous groups. Journal of Abnormal and Social Psychology, 62, 401-407.

Hosmer, L. T. (1995). Trust: The connecting link between organizational theory and philosophic ethics. Academy of Management Review, 20, 379-403.

James, L. R. (1982). Aggregation bias in estimates of perceptual agreement. Journal of Applied Psychology, 67, 219-229. 
James, L. R., Demaree, R. G., \& Wolf, G. (1984). Estimating withingroup interrater reliability with and without response bias. Journal of Applied Psychology, 69, 85-98.

Janis, I. L. (1982). Groupthink: Psychological studies of foreign policy decisions and fiascos. (2nd ed.). Boston: HoughtonMifflin.

Janssen, O., Van de Vliert, E., \& Veenstra, C. (1999). How task and person conflict shape the role of positive interdependence in management teams. Journal of Management, 25, 117-142.

Jehn, K. A. (1995). A multimethod examination of the benefits and detriments of intragroup conflict. Administrative Science Quarterly, 40, 256-282.

Jehn, K, A. (1997). A qualitative analysis of conflict types and dimensions in organizational groups. Administrative Science Quarterly, 42, 530557.

Jehn, K. A., \& Mannix, E. (1997). The dynamic nature of conflict: A longitudinal study of intragroup conflict and group performance. Manuscript submitted for publication, University of Pennsylvania, Philadelphia.

Jehn, K., Northcraft, G., \& Neale, M. (1999). Why differences make a difference: A field study of diversity, conflict, and performance in work groups. Administrative Science Quarterly, 44, 741-763.

Jones, E. E., \& Davis, K. E. (1965) From acts to dispositions: The attribution process in person perception. In L. Berkowitz (Ed,), Advances in experimental social psychology (Vol. 2, pp. 220-266). New York: Academic Press.

Korsgaard, M. A., Schweiger, D. M., \& Sapienza, H. J. (1995). Building commitment, attachment, and trust in strategic decision-making teams: The role of procedural justice. Academy of Management Journal, 3S, 60-84.

Lind, E. A., \& Tyler, T. R. (1988). The social psychology of procedural justice. New York: Plenum.

Mayer, R. C., Davis, J. H., \& Schoolman, F. D. (1995). An integrative model of organizational trust. Academy of Management Review, 20, $709-734$.

McAllister, D. J. (1995). Affect- and cognition-based trust as foundations for interpersonal cooperation in organizations. Academy of Management Journal, 38, 24-59.

Mishra, A. K. (1996). Organizational responses to crisis: The centrality of trust. In R. Kramer \& T. Tyler (Eds.), Trust in 
organizations: Frontiers of theory and research (pp. 261-287). Thousand Oaks, CA: Sage.

O'Reilly, C. A. HI, Williams, K. Y., \& Barsade, S. (1998). Demography and group performance: Does diversity help? In M. A. Neale, E. A. Mannix, \& D. Gruenfeld (Eds.), Research on managing groups and teams (Vol, 1, pp. 183-208). Greenwich, CT: JAI Press.

Pelled, L. (1996). Demographic diversity, conflict, and work group outcomes: An intervening process theory. Organization Science, 7, 615631 .

Pelled, L. H., Eisenhardt, K. M., \& Xin, K. R. (1999). Exploring the black box: An analysis of work group diversity, conflict, and performance. Administrative Science Quarterly, 44, 1-28.

Peterson, R. S. (1997). A directive leadership style in group decision making can be both virtue and vice: Evidence from elite and experimental groups. Journal of Personality and Social Psychology, 72, 1107- 1121 .

Peterson, R. S. (1999a). Can you have too much of a good thing? The Limits of voice for improving satisfaction with leaders. Personality and Social Psychology Bulletin, 25, 313-324.

Peterson, R. S. (1999b, August). Executive leadership: The case against impartiality. Paper presented at the annual Academy of Management national meetings, Chicago, IL.

Putnam, L. L. (1994). Productive conflict: Negotiation as implicit coordination. International Journal of Conflict Management, 5, 285-299.

Putnam, L. L., \& Wilson, C. (1982), Communicative strategies in organizational conflict: Reliability and validity of a measurement scale. In M. Burgoon (Ed.), Communication yearbook (Vol. 6, pp. 629 - 652). Newbury Park, CA: Sage.

Schweiger, D., Sandberg, W., \& Ragin, J. (1986). Group approaches for improving strategic decision malting: A comparative analysis of dialectical inquiry, devil's advocacy, and consensus approaches to strategic decision making. Academy of Management Journal, 29, $57-71$.

Schweiger, D., Sandberg, W., \& Rechner, P. (1989). Experiential effects of dialectical inquiry, devil's advocacy, and consensus approaches to strategic decision making. Academy of Management Journal, 32, 745-772.

Simons, T. (1993). Clash of the titans: The performance impact of top management team debate-A test of multiple contingency models. Dissertation Abstracts International, 55(01), 4729A. 
Staw, B., Sandelands, L., \& Dutton, J. (1981). Threat-rigidity effects in organizational behavior: A multilevel analysis. Administrative Science- Quarterly, 26, 501-524.

Tjosvold, D. (1991). The conflict-positive organization. Boston: Addison-Wesley.

Torrance, E. P. (1957). Group decision making and disagreement. Social Forces, 35, 314-318.

Tyler, T. R., \& Lind, E. A. (1992). A relational model of authority in groups. In M. Zanna (Ed.), Advances in experimental social psychology (Vol. 25, pp. 115-192). New York: Academic Press.

Van de Vliert, E, \& de Dreu, C. (1994), Optimizing performance by conflict stimulation. International Journal of Conflict Management, 5, 211-222.

Wall, V., \& Nolan, L, N. (1986). Perceptions of inequity, satisfaction, and conflict in task-oriented groups. Human Relations, 39, 1033-1052. Walton, R. E. (1969). Interpersonal peacemaking: Confrontations and third-party consultation. Reading, MA: Addison-Wesley.

Williams, K. Y., \& O'Reilly, C. A. III. (1998). Demography and diversity in organizations: A review of 40 years of research. In B. Staw \& R. Sutton (Eds.), Research in organizational behavior (Vol. 20, pp. 77140). Greenwich, CT: JAI Press.

Wilson, S. R., \& Waltman, M. S. (1988). Assessing the Putnam-Wilson Organizational Communication Conflict Instrument (OCCI) . Management Communication Quarterly, 1, 367-387.

Zand, D. E. (1972). Trust and managerial problem solving. Administrative Science Quarterly, 17, 229-239. 